\title{
"A VIA QUE FACILITA É A MESMA QUE DIFICULTA": estigma E ATENÇÃo EM HIV-Aids NA Estratégia SAúde \\ DA FAMÍLIA - ESF \\ Gustavo Zambenedetti ${ }^{\star}$ Nalu Silvana Both ${ }^{\star}$
}

\begin{abstract}
RESUMo
Este estudo buscou analisar a atenção em HIV-Aids na Estratégia Saúde da Família - ESF, levando-se em consideração a dinâmica do estigma associada a Aids, sob a perspectiva dos profissionais de saúde. O estudo foi realizado com duas equipes da ESF que compõem uma unidade de saúde em Porto Alegre$R S$. Foram realizadas entrevistas com os médicos, enfermeiros e técnicos de enfermagem e um grupo focal com os Agentes Comunitários de Saúde. A análise realizada se deteve sobre três eixos: a percepção dos profissionais sobre o estigma relacionado a Aids; a participação dos profissionais na dinâmica do segredo/ encobrimento/revelação do diagnóstico; a participação dos profissionais na (re)produção de estigmas. Os resultados apontaram a necessidade da dinâmica do estigma ser considerada no planejamento das ações e serviços em saúde, visando facilitar o acesso ao diagnóstico e tratamento, a construção de vínculo e confiança entre usuários e profissionais.

Palavras-chave: Síndrome da Imunodeficiência Adquirida; Estratégia Saúde da Família; estigma; práticas profissionais; atenção em saúde. \section{IT DIFFICULT": STIGMA AND HEALTH CARE IN HIV-AIDS IN Family Health Strategy - FHS}

${ }^{6}$ THE WAY THAT MAKES IT EASY IS THE SAME THAT MAKES
\end{abstract}

\begin{abstract}
This study aimed to analyze health care in HIV-AIDS in Family Health Strategy FHS, considering the dynamics of stigma associated to Aids, from the perspective of health care professional. The study was carried out with two FHS teams that are part of a health care unit in Porto Alegre-RS. Interviews with physicians,

\footnotetext{
^ Psicólogo. Mestre e Doutorando em Psicologia Social e Institucional pela Universidade Federal do Rio Grande do Sul. Professor Assistente A do Departamento de Psicologia - Universidade Estadual do Centro-Oeste (UNICENTRO) / Campus Irati-PR. Endereço: Universidade Estadual do Centro-Oeste - Campus de Irati. PR 153 Km 7 - Riozinho - CEP 84500-000 - Irati - PR.

E-mail: gugazam@yahoo.com.br Atualmente é Psicóloga (servidor público) da Secretaria de Estado da Saúde do Rio Grande do Sul. E-mail: naluboth@gmail.com
}

$\star \star$ Psicóloga. Possui mestrado em Sociologia pela Universidade Federal do Rio Grande do Sul.
\end{abstract}


nurses and nursing technicians were carried out, as well as a focal group with Health Community Agents. Analysis was based in three foci: perceptions of professional about stigma related to Aids; participation of professional in the secrecy/concealment/unveiling dynamics of diagnosis; participation of professional concerning (re)production of stigma. Results highlighted the need to consider the stigma dynamics regarding planning in health care actions and services, aiming to facilitate access to diagnosis and treatment, construction of bonds and confidence among users and professionals.

Keywords: Acquired Immunodeficiency Syndrome; Family Health Strategy; stigma; professional practices, prevention; health care.

A pesquisa que deu origem a este artigo teve como objetivo geral analisar como ocorre a atenção em HIV-Aids na Estratégia Saúde da Família-ESF, levando-se em consideração a participação dos profissionais de saúde na dinâmica do estigma associado a Aids. Pretendemos desenvolver algumas considerações iniciais sobre a Estratégia Saúde da Família, a atenção em HIV-Aids e a dinâmica do estigma, a fim de subsidiar a problematização proposta.

A ESF é uma das estratégias do Ministério da Saúde para reorganizar o sistema de saúde brasileiro. Surge em âmbito nacional em 1994, sendo denominada Programa Saúde da Família (PSF). Em 2006, com a portaria n 648 (BRASIL, 2006a) o Programa Saúde da Família passa a se chamar Estratégia Saúde da Família, mantendo suas características originais.

Entre as características do processo de trabalho da ESF, destacamos a adscrição da clientela e a territorialização, que se referem à delimitação da equipe de ESF como referência para um território geográfico e uma população de, no máximo, 4.000 habitantes, sendo recomendada a média de 3.000 habitantes (BRASIL, 2006a). A população do território adscrito é cadastrada junto à unidade de saúde, que se constitui como referência para o seu cuidado em saúde. A proximidade da unidade em relação ao território habitado pelos usuários visa facilitar o acesso e propiciar que a equipe esteja inserida no contexto social e cultural dos usuários, facilitando a formação de vínculo (FRANCO, MERHY, 2004). O vínculo diz respeito à "constituição de referências do usuário com os profissionais que deverão responsabilizar-se do cuidado de sua clientela." (FRANCO; MERHY, 2004, p. 57). A equipe mínima de ESF é constituída por um médico, um enfermeiro, dois técnicos de enfermagem, 4 - 6 Agentes Comunitários de Saúde (ACS). O ACS é um personagem bastante singular da ESF, pelo fato de ser um morador da área adscrita a unidade, além de ser responsável por ações de prevenção e promoção em saúde é considerado o elo entre a população e a unidade de saúde.

A atenção básica, em especial a ESF, passa a ser vista como um importante equipamento para as ações de atenção em HIV-Aids a partir do final da década de 1990. Até então a rede de atenção em HIV-Aids estava centrada nos hospitais, Centros de Testagem e Aconselhamento (CTA) e Ambulatórios ou Serviços de Atenção Especializada (SAE). Os CTA foram criados com a finalidade de ofertar 
diagnóstico e aconselhamento em HIV-Aids, sob os princípios de voluntariedade, confidencialidade, anonimato, agilidade e resolutividade do diagnóstico de HIV. Tais princípios estiveram em consonância com aspectos sociais e subjetivos suscitados pela epidemia, relacionados ao preconceito e discriminação das pessoas com HIV-Aids. Já os ambulatórios ou SAE realizam o tratamento das pessoas que vivem com HIV-Aids (BRASIL, 2008).

Apesar da importância fundamental destes serviços especializados, a institucionalização do SUS e a evolução da epidemia de Aids redimensionaram as ações de atenção em HIV-Aids, inserindo-as também na atenção básica. Um dos fatores que justificou esse redirecionamento foi a constatação realizada pelo Ministério da Saúde, em 1998, de que o diagnóstico de HIV ocorria tardiamente no Brasil, ou seja, quando o sistema imunológico já estava debilitado (BRASIL, 2008). Além disso, ocorreram mudanças no perfil da epidemia, caracterizada atualmente por tendências de feminilização, heterossexualização, pauperização, interiorização e juvenização (BRASIL, 2006b). Estes dois fatores passaram a justificar a necessidade de criação de novas estratégias para a ampliação do acesso à prevenção, diagnóstico e tratamento. Uma dessas estratégias envolveu a incorporação de ações na atenção básica, considerada estratégica em decorrência da abrangência de cobertura populacional e da crescente ampliação através da consolidação da ESF.

Nos anos 2000 foram publicados três manuais articulando atenção em HIV-Aids e atenção básica (BRASIL, 2003, 2005, 2006b). Estes manuais enfatizam a inserção do aconselhamento ${ }^{1}$ e o incentivo da oferta diagnóstica para o HIV (BRASIL, 2003, 2005). Indicam a proposição de ações de prevenção às DST/ HIV/Aids dentro das unidades de saúde (acolhimento, educação em saúde em sala de espera, disponibilização de insumos de prevenção e comunicação dos parceiros sexuais) e ações envolvendo a comunidade (mapeamento de grupos mais vulneráveis, encaminhamento para unidade de saúde ou outros serviços de referência, acesso a informação) (BRASIL, 2005; 2006b). As diretrizes do Ministério da Saúde orientam que as pessoas em acompanhamento nos serviços especializados possam também ser acompanhadas pelas unidades básicas, dentro de uma lógica de co-responsabilização. Dessa maneira, observamos que a atenção básica vêm se tornando uma instância cada vez mais importante na atenção em HIV-Aids, justificando sua abordagem nesse estudo.

\section{A dimensão do estigma e SEUS IMPaCtos na ATENÇÃo EM HIV-AidS}

Observamos que o pressuposto dos princípios de territorialização e adscrição da clientela, presentes na ESF, é de que eles facilitam a formação de vínculo usuário-profissional e, por conseqüência, o acesso à unidade de saúde. Mas será este um pressuposto universal?

A partir da vinculação ${ }^{2}$ com a prática assistencial em um Centro de Testagem e Aconselhamento (CTA) e na Clínica de HIV-Aids de um Ambulatório especializado, ${ }^{3}$ observamos o relato de alguns usuários que preferem realizar o 
tratamento em serviços distantes de onde residem, com receio de serem identificados ao entrar no serviço ou por receio quanto à capacidade das equipes garantirem o sigilo diagnóstico. Relatamos uma cena que expressa esses aspectos.

Cena: uma mulher, com cerca de 35 anos, procura o CTA para a testagem anti-HIV para confirmar seu diagnóstico. Relata ter realizado um teste no início do mês com resultado HIV reagente (positivo). Pergunto se ela fez o teste anterior na unidade de saúde próximo a sua casa. Ela responde que lá não faria de jeito nenhum, "porque é muita fofocaiada". Comenta que se é um drogado que vai fazer o teste, já é drogado mesmo... Mas se é a padeira do bairro [como é seu caso], todo mundo vai saber.

Pretendemos desenvolver o argumento de que nem sempre a proximidade do serviço de saúde em relação ao local de moradia facilita o acesso a ações de saúde. Nossa argumentação assenta-se sobre as especificidades da atenção em HIV-Aids, em especial a dinâmica do estigma a ela relacionada.

Existe uma diversidade de produções enfatizando aspectos do estigma relacionados a Aids. Zucchi et al. (2010) abordam a vivência de episódios de estigma e discriminação relacionados a Aids por crianças em escolas. Garrido et al. (2007) analisam a vivência de estigmas no ambiente de trabalho. Guerra e Seidl (2009) citam uma série de produções relacionando a vivência do estigma por crianças e seus familiares, com implicações na revelação do diagnóstico, aderência ao tratamento e construção de estratégias de enfrentamento. Almeida e Labronici (2007) estudaram os aspectos que motivaram cinco pessoas vivendo com HIV a não procurarem serviços do SUS para realizarem o acompanhamento de sua saúde. Através de entrevistas realizadas com estas pessoas, foi constatada a existência de um receio na procura por serviços próximos aos seus locais de residência, pelo medo de serem identificadas ou de encontrarem pessoas conhecidas. Como um modo de proteção, preferem o segredo, aumentando o sofrimento pessoal e vulnerabilidade ao adoecimento de Aids. Essa percepção é corroborada por estudo realizado por Seoane e Fortes (2009) com usuários de unidades de saúde com ESF, onde se constatou a inexistência de preocupação do usuário quanto à falta de sigilo de suas informações, a não ser em situações que envolvem doenças como a Aids, onde o preconceito ainda está presente. Estes dois últimos estudos citados, em especial, corroboram a nossa percepção de que nem sempre a proximidade com o território é vista como uma facilitadora do acesso, demandando uma atenção especial as questões éticas suscitadas.

Para compreender a dimensão do estigma em uma perspectiva dinâmica, nos apoiamos no trabalho de Erving Goffman (GOFFMAN, 2008). Segundo o autor, estigma significa marca, impressão. O termo fora criado pelos gregos, identificando uma marca corporal que designava algo extraordinário ou mau sobre o status moral de uma pessoa. Posteriormente o estigma deixou de estar relacionado a uma marca corporal, sendo relacionado aos valores atribuídos às características de uma pessoa, geralmente com caráter depreciativo. 
Para pensar como o estigma opera em nível social e subjetivo, Goffman (2008) apresenta os conceito de "identidade social", "identidade social virtual" e "identidade pessoal". A identidade social relaciona-se com os primeiros aspectos que nos permitem prever a categoria e o atributo ao qual um indivíduo pertence, sendo perpassada pela imagem corporal, vestimentas, profissão, entre outros marcadores sociais. É baseada em preconcepções, transformadas em expectativas normativas. Em relação à Aids, podemos pensar na imagem socialmente difundida no início da epidemia, associando-a aos homossexuais, prostitutas, promiscuidade e magreza. Por outro lado, a identidade social virtual diz respeito às expectativas em relação à categoria/atributos da pessoa que está a nossa frente, quando nos colocamos em relação com alguém. Já a identidade pessoal diz respeito à maneira pela qual a pessoa a qual é atribuído um estigma se relaciona e manipula as informações concernentes a ele, podendo ou não se identificar com a identidade socialmente atribuída. Uma pessoa que descobre viver com HIV pode sentir-se envergonhada e marginalizada por pensar que irão associá-la a imagens socialmente carregadas negativamente, gerando discriminação. Disso pode decorrer uma série de comportamentos e sentimentos, incluindo respostas antecipatórias e defensivas, dificuldade de aceitação do diagnóstico e reações de retraimento.

Segundo Goffman (2008), existiriam diferentes tipos de estigmas: aqueles que são visíveis e aqueles que dependem de uma revelação. O estigma da Aids é caracterizado eminentemente pela presença de uma informação acerca do diagnóstico de HIV, inserida em uma dinâmica de encobrimento/segredo/revelação. Questões comuns após o diagnóstico são: contar para alguém? Quem? Como? Quando? Nas relações familiares e sociais, uma série de técnicas são usadas para propiciar o controle e gestão da informação. Uma das "estratégia[s] de encobrimento é apresentar os signos de seu estigma como signos de um outro atributo que seja um estigma menos significativo" (GOFFMAN, 2008, p. 106). Nesse sentido, uma pessoa que vive com HIV pode justificar o uso do preservativo aos seus parceiros alegando ter hepatite $\mathrm{C}$, considerada uma doença menos estigmatizante. Algumas pessoas com Aids trocam a embalagem das medicações, substituindo um signo da Aids por outro que não desperte atenção. Esses são exemplos das estratégias utilizadas na gestão e controle da informação diagnóstica.

O elemento central entre as pessoas soropositivas para o HIV é o fato de seu estigma não ser visível fisicamente ${ }^{4}$, dependendo de uma revelação. Porém, diferentemente de alguns estigmas que geram comoção ou compaixão, a Aids muitas vezes gera reações de culpabilização, a partir da interpretação de que é algo que poderia ter sido evitado ou que é algo proveniente de "algo errado e feio". Segundo Seffner (1998), no início da epidemia era comum a atribuição dos "culpados", como homossexuais e pessoas consideradas promíscuas, e dos "inocentes", como crianças, mulheres e hemofílicos. O impacto dessa representação é que a revelação de um diagnóstico que gera compaixão geralmente ocorre com maior facilidade, principalmente entre as pessoas mais íntimas, das quais seria esperado apoio. No caso da Aids, no entanto, observamos reações ambíguas, 
em decorrência da possibilidade de aceitação ou rejeição e culpabilização. Nesse sentido, "as pessoas íntimas podem tornar-se aquelas em relação às quais ele mais se preocupa em esconder algo vergonhoso" (GOFFMAN, 2008, p. 64).

Diante disso, delimitamos como questão norteadora da pesquisa: "Como ocorre a atenção em HIV-Aids em uma unidade da Estratégia Saúde da Família (ESF) no município de Porto Alegre-RS, considerando-se a participação dos profissionais de saúde na dinâmica do estigma que envolve o diagnóstico de HIV?". Tendo por base a existência de uma série de estudos sobre a vivência do estigma pelas pessoas com HIV-Aids e/ou seus familiares, consideramos relevante investigar a percepção dos profissionais das equipes de ESF sobre este aspecto e o modo como participam de sua dinâmica.

\section{MéTodo}

Utilizamos a abordagem qualitativa, inserida na perspectiva da pesquisa social em saúde. Minayo (1992) compreende a atividade de pesquisa como a atividade básica da ciência na sua indagação e descoberta da realidade. A peculiaridade da pesquisa social é a sua "carga histórica e, assim como as teorias sociais, reflete posições frente à realidade, momentos do desenvolvimento e da dinâmica social, preocupações e interesses de classes e de grupos determinados" (MINAYO, 1992, p. 23). Esta abordagem é consoante com a compreensão de que a Aids não constitui apenas um evento biomédico, mas sim um fenômeno ou problema social complexo (SEFFNER, 1998), constituído por uma "epidemia de significações" (TREICHLER, 1998, p. 357, tradução nossa). Segundo Treichler (1998, p. 357) a Aids é simultaneamente uma epidemia de ordem viral e de significações, perpassadas por crenças e valores culturais. São esses diferentes significados e valores atribuídos a determinado fenômeno que a pesquisa qualitativa possibilita compreender.

A pesquisa na qual baseia-se esse artigo foi realizada em 2009, com os integrantes de duas equipes de ESF de uma mesma unidade de saúde do município de Porto Alegre: 2 médicos, 2 enfermeiros, 4 técnicos de enfermagem e 7 Agentes Comunitários de Saúde-ACS.

A escolha da equipe levou em consideração alguns aspectos: 1) pertencimento da unidade à gerência distrital Partenon-Lomba do Pinheiro - que apresenta a maior incidência de Aids no município de Porto Alegre (PORTO ALEGRE, 2008); 2) Disponibilidade e desejo da equipe para participar da pesquisa. A partir disso estabeleceu-se contato com a Gerência Distrital e com uma unidade de ESF, que concordaram com a realização da pesquisa.

Como técnicas de coleta de dados utilizamos entrevistas individuais semi-estruturadas, realizadas com os médicos, enfermeiros e técnicos de enfermagem e grupo focal, realizado com os ACS. A entrevista e o grupo focal tem como objetivo captar percepções, opiniões e sentimentos frente a um tema determinado. A diferença entre ambos é que, no caso do grupo focal, esta captação ocorre em ambiente de interação (TRAD, 2009; MINAYO, 1992). A utilização do grupo focal foi adequada à abordagem dos ACS pelo fato destes constituírem um grupo 
homogêneo e numericamente significativo. O critério de homogeneidade levou em consideração a função profissional, designando posições semelhantes nas relações de poder dentro da equipe de saúde. Esta condição facilita aos sujeitos expressarem suas opiniões com maior liberdade. Além disso, o trabalho dos ACS tem peculiaridades em relação ao trabalho dos demais membros da equipe, em decorrência da exigência de que eles atuem na mesma área onde residem.

Os dados foram registrados em gravador e posteriormente transcritos, visando auxiliar a sistematização dos dados e análise. Esta pesquisa seguiu as diretrizes e normas regulamentadas pela resolução nº 196/96 (BRASIL, 1996).

Os dados foram organizados através da análise de conteúdo (MINAYO, 1992; GOMES, 1994). O primeiro passo consistiu na seleção e leitura exaustiva do material transcrito. A seguir, delinearam-se temas centrais, constituídos por núcleos comuns de significação, os quais foram interpretados segundo uma base conceitual e bibliográfica. Através destes procedimentos selecionamos três eixos considerados relevantes para a análise neste artigo: percepção dos profissionais sobre o estigma relacionado ao HIV-Aids; participação dos profissionais na dinâmica do segredo/encobrimento/revelação do diagnóstico; participação dos profissionais da ESF na (re)produção de estigmas.

Com a finalidade de não identificar os participantes da pesquisa, os excertos de falas utilizados foram identificados apenas por números (01 a 15).

\section{Resultados e Discussão}

\section{Percepção dos profissionais sobre o estigma}

A maioria dos entrevistados acredita que o preconceito e o estigma em relação ao HIV ainda é bastante presente. "Tem preconceito ainda. Ainda tem pessoas que acham que HIV pega de tu conviver junto, de tu apertar a mão, de tu morar junto, beijar, abraçar, tem gente que ainda pensa assim" (07). Eles acreditam que um dos principais motivos é a desinformação. Porém, quando pensam sobre o início da epidemia em comparação com o estágio atual, a maior parte dos entrevistados refere ter ocorrido uma diminuição do preconceito, o qual estaria relacionado aos avanços no tratamento e ao fato de que "HIV não assusta mais tanto" (04). Esta percepção está em consonância com estudo realizado por Garcia e Koyoma (2008), com o intuito de identificar a prevalência da intenção de atitudes discriminatórias em dois momentos (1998 e 2005) da epidemia brasileira de HIV/Aids e possíveis mudanças ocorridas. Foi constatada redução da intenção de atitudes discriminatórias em alguns aspectos, como a obrigatoriedade do teste anti-HIV para admissão no emprego ou para a entrada de estrangeiros no país. Porém, não houve redução significativa em outros pontos, como na aceitação de que uma casa de apoio a pessoas com HIV-Aids fosse construída ao lado de sua casa (GARCIA; KOYOMA, 2008). 
Entre os ACS foi relatada também a existência de uma "banalização" da Aids por parte de alguns usuários. Compreendem que a banalização da Aids significa percebê-la como algo comum, que não provoca mais medo ou preocupação, dificultando o trabalho de prevenção: "parece que a Aids virou uma doença crônica, que vem no posto e tem tratamento, que nem hipertensão e diabetes" (09). Victora, Knauth e Hassen (2000) relatam o fenômeno de banalização da Aids em contextos comunitários específicos estudados na década de 1990, no município de Porto Alegre-RS. Segundo as autoras, a banalização era compreendida como uma percepção de familiaridade com a doença, em decorrência de sua alta prevalência no contexto comunitário. Outro fator que contribuía para a banalização era a percepção de que a presença de tratamentos minorava a gravidade da doença (VICTORA, KNAUTH, HASSEN, 2000).

Alguns profissionais acreditam que o estigma e o preconceito dificultam a revelação do diagnóstico à equipe e o acesso à unidade de saúde local.

O paciente com HIV, geralmente ele tem um acanhamento pra chegar na unidade. [...] eu acredito que eles ficam numa situação vexados pelo diagnóstico e a forma como isso pode repercutir aqui na unidade é que é o mais próximo, né, onde muitas vezes eles conhecem a família, o irmão, sei lá quem, parente ou os amigos, e ai os amigos ficam sabendo de alguma forma, e eles não gostariam que isso se espalhasse. (01)

Há alguns casos envolvendo a questão do HIV que se tornam de conhecimento de toda a equipe. Foi relatado, por exemplo, a situação de uma jovem vivendo com HIV, usuária de crack e que se desloca constantemente dentro da comunidade. Os aspectos que estigmatizam a jovem dentro da comunidade são vistos pela equipe sob a ótica da vulnerabilidade, designando a necessidade de uma atenção diferenciada, em consonância com o princípio de equidade presente no Sistema Único de Saúde (BRASIL, 1990). O(s) estigma(s) reverte(m)-se, neste caso, como fatores que justificam a necessidade de um acolhimento diferenciado e prioridade no acesso às ações em saúde.

\section{ParticipaÇão dos profissionais na dinÂMica do Segredo/ ENCOBRIMENTO/REVELAÇÃO DO DIAGNÓSTICO}

A presença de um estigma que depende de uma revelação para ser descoberto, como é o caso da Aids, muitas vezes é permeado por uma dinâmica de segredo/revelação/encobrimento. Os relatos dos profissionais nos auxiliam a compreender as posições ocupadas pelos mesmos diante de tal dinâmica, participando do processo de gestão e controle da informação. Um importante fator nessa dinâmica diz respeito ao modo pelo qual o profissional teve acesso ao diagnóstico: pelo próprio usuário; por outro profissional da equipe ou prontuário; por outras pessoas do território atendido. 
Quando o diagnóstico é compartilhado entre o usuário e o profissional, tal temática se torna passível de emergir na relação de cuidado. Os ACS, por exemplo, abordam o assunto nas visitas domiciliares, perguntando como a pessoa está, se vai às consultas, se está tomando medicações, etc. Mas há também situações nas quais, apesar do compartilhamento do diagnóstico, o assunto "Aids" se torna um tabu, sobre o qual não se pode falar/nomear. Na abordagem com os usuários, a palavra Aids ou HIV não costuma ser mencionada, sendo um assunto subentendido nas conversas. Pensamos que essa ocultação do nome ocorre em função da discrição que tal assunto envolve, pois em algumas situações as pessoas próximas não sabem do diagnóstico.

Por outro lado, nas situações em que o diagnóstico não é revelado pelo usuário, mas sim por outro profissional ou por outras pessoas do território, a partir das relações de vizinhança dos ACS, observamos outras formas de gestão e controle da informação. Nestas situações, os profissionais relataram preferir não tocar no assunto com o usuário. Constatamos que os profissionais têm diferentes opiniões sobre quais categorias profissionais podem ter acesso a revelação do diagnóstico e em quais situações. O principal ponto de tensionamento na equipe diz respeito à função do ACS. Um dos profissionais de nível superior, por exemplo, acredita que os ACS não deveriam ter conhecimento dos diagnósticos de HIV. Justifica tal posicionamento por acreditar que o fato de morar e trabalhar na mesma área dificulta ao ACS o sigilo das informações. Os ACS, no entanto, afirmam que a revelação do diagnóstico deve ocorrer, pois auxilia seu trabalho junto aos usuários. Apesar disso, não há consenso sobre o modo como o processo de compartilhamento do diagnóstico na equipe deve ser conduzido. Oliveira et al. (2004) apontam que os ACS ocupam uma dupla posição de enunciação, ora como homens/mulheres que vivem na comunidade, ora como profissionais da saúde. Pensamos que a duplicidade enunciativa que constitui a posição do ACS pode ser interpretada de forma paradoxal pelo restante da equipe e usuários, colocando em dúvida a posição assumida pelos ACS a partir da revelação de um diagnóstico perpassado por estigmas. $\mathrm{Ou}$ seja, o conhecimento do diagnóstico pode ser interpretado como uma "informação em saúde", inserido na dimensão das práticas de cuidado; ou, pode ser interpretada como uma "fofoca", disseminando-se pela comunidade.

Em relação a essa dupla posição enunciativa, os relatos dos ACS evidenciam que tanto a "fofoca" quanto à "informação em saúde" fazem parte de seu cotidiano de trabalho. A fofoca é caracterizada pelas informações provenientes das relações de vizinhança, a princípio sem um propósito definido. Por outro lado, o que estamos chamando de "informação em saúde" constitui-se como uma informação proveniente da unidade de saúde e/ou relação profissional, com a finalidade de ser utilizada no âmbito das práticas de cuidado em saúde. Segundo os relatos dos ACS, eles transformam as fofocas em informações em saúde. Ou seja, eles obtêm dados a partir das relações de vizinhança que dão subsídios para a sua atuação junto à equipe de saúde. Como exemplo, relatam a situação de um homem que vivia com Aids e faleceu. Ele se relacionava com duas mulheres e uma delas recebia Visitas Domicilares (VD) da ACS. Mas essas mulheres nunca mencionaram o assunto com a ACS, que soube dessas relações "por outras pesso- 
as": "vai na casa de um, o outro conta [...] Os dois maridos não sabiam de nada, e uma não sabia da outra. Jamais vou chegar pra ela e falar, porque ela não me contou" (12). AACS acredita que as mulheres não sabiam que ele tinha HIV. Esta cena é composta por informações provenientes da posição que ocupa enquanto profissional de saúde (a informação de que o rapaz tinha Aids); e da posição de moradora da área (a informação, entendida como "fofoca", de que as duas mulheres se relacionavam com o rapaz). Tais informações produziram um dilema, expresso pela ACS: "sim, não posso chegar pras mulheres e dizer pra elas: vai lá no posto fazer exame porque o cara que tu te relacionava tinha Aids!" (12). Para preservar o sigilo, ela passou a incentivar essas mulheres a procurar a unidade de saúde por outros motivos: "já fez os preventivos esse ano?" (12). Ao mesmo tempo, relatou a situação para o médico, sugerindo que ele abordasse o tema da prevenção na consulta, propiciando a avaliação de situações de risco e a oferta do teste anti-HIV. Nesse processo, o que era considerado uma fofoca se tornou uma informação em saúde, inserida nas relações de cuidado e prevenção, revelandose como uma das potencialidades do trabalho no território propiciado pela ESF.

Apesar disso, não poderíamos deixar de mencionar que a situação relatada evidencia que a prevenção ainda é disparada por uma estratégia de controle, baseada na identificação do "portador de HIV" e de seus parceiros. Na situação relatada, as duas mulheres se tornaram alvo de medidas preventivas, incluindo a solicitação do teste anti-HIV, na medida em que a equipe soube que elas se relacionaram com uma pessoa com HIV. Porém, devemos considerar a existência de pessoas com HIV que não são identificadas pelos profissionais, assim como pessoas que tem HIV e desconhecem seu status sorológico para o HIV. Sendo assim, deveria ser um pressuposto, na ESF, o estímulo aos exames preventivos e o acesso a ações de prevenção ao HIV à população de modo geral, e não apenas quando se identifica um "potencial transmissor".

Observamos que um dos vetores desta discussão é a questão do território e o quanto ele pode facilitar ou dificultar a atenção. No grupo realizado com os ACS, um deles sintetizou o paradoxo de viver e trabalhar na mesma área: "A via que facilita é a mesma que dificulta" (14). Eles acreditam que o fato de morarem na região pode tanto atrapalhar quanto ajudar na sua atuação, justamente por serem situados em uma dupla função enunciativa que pode gerar duplicidade de expectativas. Apesar disso, os ACS apostam na possibilidade de construção de vínculo e relações de confiança, expressando uma relação ética do cuidado.

Tais considerações estão em consonância com os dados encontrados em pesquisa realizada por Ferreira e Nichiata (2008) e Abdala e Nichiata (2008). Ao investigarem os fatores que facilitam e dificultam a abertura do sigilo do diagnóstico de HIV por usuárias que freqüentam o PSF, Ferreira e Nichiata (2008) encontraram resultados que apontam que as mulheres revelam o diagnóstico quando o mesmo foi feito na unidade, quando sentem que são melhor atendidas em função do diagnóstico, quando tem vínculo e confiam. Por outro lado não revelam o diagnóstico quando a atitude do profissional gera medo e insegurança, não confiam por medo da quebra de sigilo ou acham que já tem tudo o que precisam no serviço especializado. Já o estudo realizado por Abdala e Nichiata (2008), inves- 
tigando a abertura da privacidade e do sigilo diagnóstico na perspectiva dos profissionais do PSF, apontou que ela exige condições para ser efetivada, sendo que o acolhimento é uma das principais delas. Nesse sentido, o principal fator para a revelação do diagnóstico e estabelecimento de uma relação de cuidado não é garantido apenas pelo território ou facilidade de acesso físico a unidade de saúde, mas sim a definição do vínculo e estabelecimento de uma relação de confiança.

Em relação ao compartilhamento do diagnóstico na equipe, o trabalho de Abdala e Nichiata (2008) traz importantes contribuições ao sugerir a inclusão do usuário nesse processo - aspecto que não foi mencionado pelos participantes de nossa pesquisa. Sugere-se que, no momento da revelação do diagnóstico, ocorra a abordagem da possibilidade de outros profissionais terem acesso a tal informação, negociando-se em que momento, por quais motivos e quais profissionais podem ter acesso. A inclusão do usuário nesse processo pode facilitar a abordagem dos profissionais de saúde e propiciar relações de sigilo e confiança ao invés de encobrimento.

\section{(RE)PROdUÇão de ESTIGMAS NAS AÇÕES dOS PROFISSIONAIS DA ESF}

No decorrer da investigação observamos que, assim como a equipe pode atuar no sentido da desconstrução de estigmas, pode também atuar na sua reprodução. Foi possível identificar alguns modos de relação que a equipe estabelece com a atenção em HIV-Aids que (re)produzem e reforçam alguns estigmas.

Um desses estigmas remete à associação entre Aids e morte. Tal associação foi evidenciada por um cartaz produzido pela equipe e afixado nas paredes da unidade, contendo o seguinte texto "Basta, Aids mata. Use camisinha". Ao lado dessa frase havia a figura de uma camisinha. Durante as entrevistas inserimos como questão: "há cartazes sobre o tema prevenção ao HIV afixado na unidade?". "O que você(s) pensam sobre o que está escrito neste cartaz?". Grande parte dos entrevistados respondeu não lembrar da presença de cartazes sobre prevenção ao HIV na unidade, evidenciando a naturalização e burocratização com a qual os cartazes passaram a ser (não)vistos. No grupo realizado com os ACS os cartazes também não foram lembrados, em um primeiro momento. Porém, um dos ACS saiu da sala para verificar. No retorno ao grupo, informou aos demais participantes sobre a presença de cartazes confeccionados pela equipe no dia mundial da Aids, como uma forma de lembrar as pessoas sobre a necessidade de prevenção.

Ao ser colocado em discussão no grupo focal, tal cartaz gerou controvérsia. Um dos ACS relatou que a afirmação presente no cartaz não fazia mais sentido, em função da evolução do tratamento para a Aids. Outros concordaram com a frase presente no cartaz, acreditando que ela poderia ter uma função educativa/ preventiva. Um dos ACS comentou que a Aids está um pouco esquecida, principalmente em função do crack ser o "assunto do momento". Este mesmo ACS afirmou que deveria haver propagandas mostrando a "cara da Aids", assim como existem propagandas ${ }^{5}$ sobre o crack mostrando pessoas mal vestidas, sujas, jogadas no chão, com caras e feições monstruosas - aspectos que constituiriam a "cara do crack", na concepção deste ACS. Questionados sobre a existência de 
uma "cara da Aids", eles confirmam a sua existência. Em tom de pergunta-afirmação, um deles responde: "o que é o final de uma pessoa com Aids [referindose a situação de hospitalização]? O que é um corpo de uma pessoa [referindo-se a magreza]? A Aids tem uma imagem!". Afirma ainda que "a imagem é uma coisa que choca e faz tu pensar, parar" (12).

Desta situação destacamos dois aspectos para a análise: a (re)produção de estigmas e a relação entre estigma e estratégias de prevenção. A (re)produção do estigma nas práticas profissionais ocorre através da associação da Aids com a morte e com uma marca corporal, designada pelos ACS como "a cara da Aids". A associação Aids-morte surgiu no início da epidemia, em decorrência da ausência de tratamentos e da alta taxa de mortalidade associada à Aids. Com o surgimento do tratamento anti-retroviral e a política brasileira de distribuição gratuita e universal de medicamentos, houve uma grande mudança na qualidade de vida das pessoas vivendo com HIV-Aids. De "doença que mata" a Aids passou a ser considerada uma doença de curso crônico, passível de tratamento. A frase veiculada no cartaz assenta-se em uma estratégia educativa baseada no amedrontamento e na idéia de que a informação de cunho biomédico serviria para mobilizar as pessoas na direção da prevenção. Tal cartaz é direcionado às pessoas que supostamente não estão infectadas, na expectativa de que sintam medo e adotem estratégias preventivas, designando a compreensão de que a prevenção significa evitar o contato com o agente transmissor de determinada doença. Ao restringirem a prevenção a tal concepção, negligenciam-se as pessoas que tem HIV e freqüentam a unidade, sendo submetidas a uma informação que reforça um estigma. A associação com a morte também pode ter como conseqüência o medo e conseqüente evitação do teste anti-HIV, em decorrência da possibilidade de se confrontar com um resultado positivo.

A utilização da "cara da Aids" como recurso preventivo remete a noção de grupos de risco, difundida no início da epidemia de Aids (AYRES et al., 2009). Esta estratégia era baseada na identificação de potenciais transmissores. Nos EUA, os potenciais transmissores foram identificados como os chamados quatro Hs: homossexuais, hemofílicos, heroínomanos e haitianos (AYRES et al., 2009). No Brasil, os heroinômanos e os haitianos não condiziam com a realidade local, sendo os mesmos substituídos pela figura do usuário de drogas injetáveis e pelas profissionais do sexo. Segundo Ayres et al. (2009, p. 124) a estratégia dos grupos de risco "além de êxitos técnicos muito restritos, produziram em grande escala estigma e preconceito". Em substituição a esta estratégia surgiu a noção de comportamento de risco, visando retirar o caráter estigmatizador dos grupos de risco e universalizar a preocupação com o problema, estimulando o comportamento preventivo. Como "efeito colateral", tal estratégia criou a tendência a culpabilização individual. A terceira estratégia de prevenção à Aids passou a ser pautada na noção de vulnerabilidade, compreendida como:

esse movimento de considerar a chance de exposição das pessoas ao adoecimento como a resultante de um conjunto de aspectos não apenas individuais, mas também coletivos, contextuais, que acarretam maior suscetibilidade à infecção 
e ao adoecimento e, de modo inseparável, maior ou menor disponibilidade de recursos de todas as ordens para se proteger de ambos (AYRES et al., 2009, p. 127).

As análises de vulnerabilidade são constituídas por três componentes: o individual, o programático ou institucional e o social. E a inter-relação dos três componentes que determinará o grau de vulnerabilidade de cada sujeito e/ou grupo. Desse modo, apesar de todos estarem relacionados com o problema da Aids, não estão envolvidos de modo igual. Apesar da literatura enfatizar a adoção da estratégia da vulnerabilidade, a análise realizada evidencia que a estratégia dos grupos de risco permanece permeando as práticas profissionais.

Estudos têm apontado a necessidade de ações preventivas que envolvam diferentes perspectivas de educação em saúde, para além da abordagem informativa, biomédica ou centrada no amedrontamento. "As epidemias, especialmente a de Aids, têm nos ensinado que a prevenção não deve ser reduzida a campanhas de massa, distribuição de materiais educativos e veiculação de informações qualificadas" (BRASIL, 2001, p. 33). A crítica não é direcionada a abordagem informativa em si - já que a informação também tem seu papel na educação em saúde - mas ao modo prescritivo como é trabalhada e ao fato de muitas vezes se constituir como a única alternativa de abordagem nos serviços de saúde (MEYER et al., 2006). Seffner (1998) afirma que a estratégia mais eficiente é associar a Aids com o lúdico, o prazer, e a partir daí internalizar uma cultura de prevenção e cuidado. Paiva (2000) também afirma a necessidade de metodologias participativas e construtivistas nas abordagens preventivas no campo da sexualidade. A aposta deve ser na construção de sujeitos sexuais, que possam pensar sobre suas relações e decisões no campo da sexualidade.

\section{CONSIDERaÇões FINAIS}

A partir da dinâmica do estigma apresentada por Goffman (2008) e da relação estabelecida com a Aids, é possível compreendermos a complexidade que se coloca no momento em que as políticas públicas se preocupam em estruturar serviços e ações nessa área.

A análise realizada buscou evidenciar o modo como a dinâmica do estigma perpassa as relações dos profissionais em saúde, exigindo o desenvolvimento de estratégias para gerir a informação do diagnóstico. Esses profissionais trabalham muitas vezes de modo a respeitar os usuários em suas demandas de sigilo e discrição, seja através do encobrimento da informação diagnóstica ou da relação de compartilhamento e sigilo. No entanto, observamos que há diferentes percepções na equipe sobre quais profissionais podem ter acesso aos diagnósticos e como tal acesso pode ocorrer. Isso sugere a necessidade de que tal tema seja discutido na equipe, visando a co-responsabilização dos profissionais com o problema em questão.

Identificamos também aspectos da equipe que reforçam alguns estigmas relacionados à Aids, como a associação Aids-morte em um cartaz produzido pela equipe e afixado nas paredes da unidade de saúde. Ou ainda, a idéia da existên- 
cia de uma "cara da Aids", representada por uma pessoa magra, agonizando em uma cama de hospital. Tal imagem atualiza o estereótipo forjado no início da epidemia, na década de 1980. Observamos, ainda, que o uso de informações que causam amedrontamento é visto pelas equipes investigadas como a única ou principal forma de mobilizar os sujeitos para a adoção de práticas preventivas. Tal compreensão denota a necessidade de discussão e incorporação de outras estratégias de educação em saúde, perpassadas pela noção de vulnerabilidade (MEYER et al., 2006; PAIVA, 2000; AYRES et al., 2009).

Por último, destacamos a necessidade de problematizar o pressuposto de que a territorialização e adscrição da clientela sempre facilitam o acesso à unidade de saúde. Para além de princípios baseados em uma lógica racional-administrativa, a organização das ações em saúde não pode deixar de considerar os aspectos sociais e subjetivos associados à doenças como a Aids. Devemos ressaltar que não estamos negando as contribuições de tais características do processo de trabalho da ESF. O que contestamos é o caráter de universalidade das pressuposições associadas a eles e a idéia de que o território, por si só, garante o vínculo e facilidade de acesso aos usuários. Para além do território sob o ponto de vista espacial, compreendemos o território constituído do ponto de vista relacional, no qual as pessoas conferem diferentes sentidos a ele. A frase de um ACS surge como expressão desse paradoxo criado pela relação com o território: "a via que facilita é a mesma que dificulta". Apoiados nas falas e no saber-fazer dos participantes da pesquisa, principalmente dos ACS, fazemos uma aposta no caráter extra-territorial do vínculo, baseado nas relações de confiança e acolhimento.

\section{Notas}

${ }^{1} \mathrm{O}$ aconselhamento é definido como "um diálogo baseado em uma relação de confiança que visa proporcionar à pessoa condições para que avalie seus próprios riscos, tome decisões e encontre maneiras realistas de enfrentar seus problemas relacionados às DST/HIV/Aids" (BRASIL, 2003, p. 9). ${ }^{2} \mathrm{O}$ primeiro autor atuou nesses serviços ao longo de dois anos, integrando a equipe como residente de psicologia, vinculado à Residência Integrada em Saúde da Escola de Saúde Pública do Rio Grande do Sul, ênfase em Dermatologia Sanitária. A segunda autora é aconselhadora neste serviço e uma das tutoras locais da Residência Integrada em Saúde.

${ }^{3}$ Trata-se do Ambulatório de Dermatologia Sanitária, serviço de referência estadual (RS) para o tratamento de dermatoses, hanseníase, DST e HIV-Aids. O CTA do Ambulatório de Dermatologia Sanitária foi o primeiro serviço nesta modalidade criado no Brasil, em 1988.

${ }^{4}$ Há algumas pessoas com HIV que podem também apresentar estigmas corporais, em função do processo de lipodistrofia, caracterizado pela redistribuição da gordura corporal (redução da gordura na face e membros e concentração no abdômen). Porém, mesmo nestes casos a pessoa pode justificar tais mudanças corporais por outros motivos, como doenças não associadas a estigmas, características familiares ou apenas emagrecimento.

${ }^{5}$ Referência à campanha veiculada na RBSTV a partir de 2008, no Rio Grande do Sul, tendo como lema "Crack, nem pensar". 


\section{REFERÊNCIAS}

ABDALA, F. T.de M.; NICHIATA, L. Y. I. A abertura de privacidade e o sigilo das informações sobre o HIV/Aids das mulheres atendidas pelo Programa Saúde da Família no Município de São Paulo, Brasil. Revista Saúde e Sociedade, São Paulo, v. 17, n. 2, p. 140-152, abr./jun. 2008.

ALMEIDA, M. R. de C. B de; LABRONICI, L. M. A trajetória silenciosa de pessoas portadoras do HIV contada pela história oral. Ciência \& Saúde Coletiva, Rio de Janeiro, v. 12, n. 1, p. 263-274, jan./fev. 2007.

AYRES, J. R. C. M et al. O conceito de vulnerabilidade e as Práticas de Saúde: novas perspectivas e desafios. In.: CZERESNIA, D. Promoção da Saúde: conceitos, reflexões e tendências. 2. ed. rev. ampl. Rio de Janeiro: Fiocruz, 2009. p. 121-144.

BRASIL. Lei n 8.080 , de 19 de setembro de 1990. Dispõe sobre as condições para a promoção, proteção e recuperação da saúde, a organização e o funcionamento dos serviços correspondentes e dá outras providências. Brasília, 1990. Disponível em: <http://portal.saude.gov.br/portal/arquivos/pdf/lei8080.pdf>. Acesso em: 30 julho 2012.

BRASIL. Ministério da Saúde. Resolução no 196 de 10 de outubro de 1996. Brasília: Conselho Nacional de Saúde, 1996. Disponível em: <http://conselho. saude.gov.br/resolucoes/reso_96.htm> Acesso em: 17 out. 2008.

BRASIL. Manual de Redução de Danos. Brasília: Ministério da Saúde, 2001.

BRASIL. Aconselhamento em DST/HIV/Aids para a Atenção Básica. Brasília: Ministério da Saúde, 2003.

BRASIL. Oficina de Aconselhamento em DST/HIV/AIDS para a atenção básica. Brasília: Ministério da Saúde, 2005.

BRASIL. Portaria $N^{o} 648$, de 28 de março de 2006. Aprova a Política Nacional de Atenção Básica, estabelecendo a revisão de diretrizes e normas para a organização da Atenção Básica para o Programa Saúde da Família (PSF) e o Programa Agentes Comunitários de Saúde (PACS). 2006 .

BRASIL. Ministério da Saúde. HIV/Aids, hepatites e outras DST. Cadernos de Atenção Básica, Brasília, n. 18, 2006b. (Série A. Normas e Manuais Técnicos).

BRASIL. Centros de Testagem e Aconselhamento do Brasil: desafios para a equidade e o acesso. Brasília: Ministério da Saúde, 2008. (Série A. Normas e Manuais Técnicos) 
FERREIRA, F. C.; NICHIATA, L. Y. I. Mulheres vivendo com Aids e os profissionais do Programa Saúde da Família: revelando o diagnóstico. Revista da Escola de Enfermagem/ USP, São Paulo, v. 42, n. 3, p. 483-489, jul./set. 2008.

FRANCO, T. B.; MERHY, E. E. Programa de Saúde da Família (PSF): contradições de um programa destinado à mudança do modelo tecnoassistencial. In: MERHY, E. E. et al (Org.). O trabalho em saúde: olhando e experienciando o SUS no cotidiano. 2. ed. São Paulo: Hucitec, 2004. p. 55-124.

GARCIA, S.; KOYAMA, M. A. H. Estigma, discriminação e HIV/Aids no contexto brasileiro, 1998 e 2005. Revista de Saúde Pública, [S.1.], v. 42, n. 3, p 72-83, mai.jun. 2008.

GARRIDO, P. B. et al. Aids, estigma e desemprego: implicações para os serviços de saúde. Revista de Saúde Pública, São Paulo, v. 41, Suplemento, p. 72-79, 2007.

GOFFMAN, E. Estigma: notas sobre a manipulação da identidade deteriorada. Rio de Janeiro: LTC, 2008.

GOMES, R. Análise de dados em pesquisa qualitativa. In.: MINAYO, M. C. de S. (Org.). Pesquisa social: teoria, método e criatividade. Rio de Janeiro: Vozes, 1994. p. $67-80$.

GUERRA, C. P. P.; SEIDL, E. M. F. Crianças e adolescentes com HIV/AIDS: revisão de estudos sobre revelação do diagnóstico, adesão e estigma. Paidéia, Ribeirão Preto, v. 19, n. 42, p. 59-65, jan./abr. 2009.

MEYER, D. E. E. et al. "Você aprende. A gente ensina?": interrogando relações entre educação e saúde desde a perspectiva da vulnerabilidade. Cadernos de Saúde Pública, Rio de Janeiro, v. 22, n. 6, p. 1335-1342, jun. 2006.

MINAYO, M. C.de S. O desafio do conhecimento: Pesquisa Qualitativa em Saúde. Rio de Janeiro: Hucitec, 1992.

OLIVEIRA, D. L. L. C. et al. A negociação do sexo seguro na TV: discursos de gênero nas falas de Agentes Comunitárias de Saúde do Programa Saúde da Família de Porto Alegre, Rio Grande do Sul, Brasil. Cadernos de Saúde Pública, Rio de Janeiro, v. 20, n. 5, p. 1309-1318, set./out. 2004.

PAIVA, V. Fazendo arte com a camisinha: sexualidades jovens em tempos de Aids. São Paulo: Summus, 2000.

PORTO ALEGRE (Prefeitura). Secretaria Municipal de Saúde. Boletim Epidemiológico. Ano X, n. 36, fev. 2008. 
SEFFNER, F. O conceito de vulnerabilidade: uma ferramenta útil em seu consultório. Aletheia (ULBRA), Canoas, v. 7, p. 53-58, jan./jul. 1998.

SEOANE, A. F.; FORTES, P. A. C. A percepção do usuário do Programa Saúde da Família sobre a privacidade e a confidencialidade de suas informações. Revista Saúde e Sociedade, São Paulo, v. 18, n. 1, p. 42-49, jan./mar. 2009.

TRAD, L. A. B. Grupos focais: conceitos, procedimentos e reflexões baseadas em experiências com o uso da técnica em pesquisas de saúde. Physis, Rio de Janeiro, v. 19, n. 3, p. 777-796, jul./set. 2009.

TREICHLER, P. AIDS, homophobia, and biomedical discourse: an epidemic of signification. In: PARKER, R.; AGGLETON, P (Org.). Culture, society and sexuality: a reader. Califórnia: UCL, 1998. p. 357386. Disponível em: <http://experienceage.com/femeti/femetimgt/ img_circular/Cambridge $\% 20$ University $\% 20$ Press $\% 20-\% 20$ Culture, $\% 20$ Society $\% 20$ and $\% 20$ Sexuality.pdf\#page=345>. Acesso em: 24 jul. 2012 .

VICTORA, C. G.; KNAUTH, D. R.; HASSEN, M. N. A. Pesquisa qualitativa em saúde: uma introdução ao tema. Porto Alegre: Tomo, 2000.

ZUCCHI, E. M. et al. Estigma e discriminação vividos na escola por crianças e jovens órfãos por Aids. Educação e Pesquisa, São Paulo, v. 36, n. 3, p. 719-734, dez. 2010.

Recebido em: 17 de maio de 2011

Aceito em: 13 de agosto de 2012 
